\title{
ADUBAC̃̃O ANTECIPADA NA CULTURA DA SOJA COM SUPERFOSFATO TRIPLO E CLORETO DE POTÁSSIO REVESTIDOS POR POLÍMEROS
}

\author{
Antecipated fertilization on soybean with triple superphosphate \\ and potassium chloride coated with polymers
}

\author{
Roni Fernandes Guareschi', Paulo Roberto Gazolla², Adriano Perin², José Matheus Kondo Santini²
}

\begin{abstract}
RESUMO
Neste trabalho, objetivou-se comparar épocas e doses de aplicação do superfosfato triplo (SFT) cloreto de potássio (KCl) com e sem revestimento por polímero no desempenho produtivo da soja em condições edafoclimáticas de cerrado. O experimento foi realizado em Rio Verde, GO, em um Latossolo Vermelho distroférrico. Os tratamentos foram dispostos em delineamento de blocos ao acaso, em esquema fatorial $2 \times 2 \times 2+1$. O primeiro fator foi constituído pelos fertilizantes $\mathrm{SFT}$ e $\mathrm{KCl}$ revestidos ou não por polímeros, o segundo por duas doses de fósforo e potássio $\left(40+40\right.$ e $80+80 \mathrm{~kg} \mathrm{ha}^{-1} \mathrm{P}_{2} \mathrm{O}_{5}$ e $\left.\mathrm{K}_{2} \mathrm{O}\right)$, e o terceiro, por duas épocas de aplicação dos fertilizantes (15 dias antes da semeadura e na semeadura). Inclui-se ainda, um tratamento testemunha sem adubação. Foi avaliada a produção de biomassa, a produtividade de grãos e componentes de produtividade. Houve resposta à aplicação da adubação com P e K na produção de massa fresca e produtividade, sendo a ausência de adubação prejudicial ao desenvolvimento da cultura da soja. A aplicação a lanço de superfosfato triplo e cloreto de potássio, revestidos por polímeros 15 dias antes da semeadura, proporcionou maior produção de massa seca, número de vagens por planta e produtividade de grãos de soja em relação aos fertilizantes convencionais. Quando aplicados na semeadura, os fertilizantes convencionais e fertilizantes revestidos por polímeros conferiram a mesma produção de massa seca e produtividade de grãos de soja.
\end{abstract}

Termos para indexação: Glycine max, fertilizante de liberação controlada, nutrição de plantas.

\section{ABSTRACT}

The objetive of this work was to compare times and application rates of triple superphosphate (TSF) and potassium chloride $(\mathrm{KCl})$ with and without polymer coating on soybean yield performance in the cerrado environmental conditions. The experiment was conducted in Rio Verde, GO, in an Oxisol. Treatments were arranged in a randomized block design, in factorial $2 \times 2 \times 2+1$. The first factor consisted by fertilizer TSF and $\mathrm{KCl}$ coated or not by polymer, the second by two doses of phosphorus and potassium $(40+40$ and 80 $+80 \mathrm{~kg} \mathrm{ha}^{-1} \mathrm{P}_{2} \mathrm{O}_{5}$ and $\mathrm{K}_{2} \mathrm{O}$, respectively), and the third by two times of application fertilizer (15 days before sowing and at sowing). It also includes a treatment control without fertilization. Biomass yield, grain yield and yield components were evaluated. There was a response to the application of fertilizer $\mathrm{P}$ and $\mathrm{K}$ in fresh mass production and productivity, with the absence of fertilizer detrimental to the development of soybean. The broadcast application of superphosphate and potassium chloride coated polymer 15 days before sowing promoted dry matter yield, number of pods per plant and grain yield of soybeans compared to conventional fertilizer. When applied at sowing, the conventional fertilizer and slow release fertilizers promoted the same dry matter yield and grain yield of soybeans.

Index terms: Glycine max, slow release fertilizer, plant nutrition.

\section{(Recebido em 22 de fevereiro de 2010 e aprovado em 22 de março de 2011)}

\section{INTRODUÇÃO}

Um dos fatores que apresentam maior custo para o produtor de soja em sistema de plantio direto no estado de Goiás são os fertilizantes, pois este insumo chega a representar aproximadamente $22,4 \%$ do custo de produção (GUARESCHI et al., 2008; Companhia Nacional de Abastecimento - CONAB, 2010).

As exigências nutricionais de uma cultura podem ser supridas pelo fornecimento de doses equilibradas de fertilizantes, combinadas com a época e modo de aplicação. Assim, tais características definem a estratégia de adubação das culturas, que podem variar em função das condições de solo, da planta e do ambiente (MENDONÇA et al., 2007).

A adoção do sistema de plantio direto proporciona melhoria em atributos físicos, químicos e biológicos do solo e a introdução de culturas de cobertura, possibilitando a adubação do sistema, com a antecipação dessa prática em relação à semeadura (SILVA; ROSOLEM, 2001; PAVINATO; CERETA, 2004; BERNARDI et al., 2009). Sendo assim, Matos et al. (2006) mencionam que a adubação antecipada reduz o tempo nas paradas para o

\footnotetext{
${ }^{1}$ Instituto Federal de Educação, Ciência e Tecnologia Goiano - campus Rio Verde - Rua Caiponia - 994 - centro - $75915-000$ - Montividiu, GO guareschiecotarelli@hotmail.com

${ }^{2}$ Instituto Federal de Educação, Ciência e Tecnologia Goiano - Rio Verde, GO
}

Ciênc. agrotec., Lavras, v. 35, n. 4, p. 643-648, jul./ago., 2011 
abastecimento da semeadora-adubadora, redução do número de conjuntos trator-semeadura e dos custos operacionais, possibilitando, desta forma, aumentar a receita líquida se comparado ao sistema tradicional, independentemente do período de semeadura. Para Lana et al. (2003), a adubação antecipada, aplicada até cinco meses antes da semeadura, não influenciou a produtividade da soja, comparativamente à aplicação de adubação na semeadura. Similarmente, Pöttker (1999) avaliou o efeito do teor de $\mathrm{P}$ do solo sobre a eficiência da adubação na linha de semeadura e a lanço na superfície do solo e concluiu que, para a soja, o modo de aplicação não interferiu no rendimento de grãos. Amoacy (2003) relata diversos resultados que indicam a viabilidade da adubação fosfatada em superfície, desde que os teores de $\mathrm{P}$ no solo estejam em níveis altos, que não haja impedimento à infiltração e que a distribuição das chuvas seja homogênea.

A adubação com potássio na cultura da soja, normalmente é realizada aplicando-se parte dos fertilizantes no sulco de semeadura e parte em cobertura. Porém, em algumas condições, tais como grandes quantidades de fertilizante aplicado na semeadura, existe a possibilidade de antecipação dessas adubações, aplicando-se, a lanço, antes da semeadura. Por sua vez, a aplicação de altas doses de potássio (acima de $80 \mathrm{~kg} \mathrm{ha}^{-1}$ ), no sulco de semeadura, deve ser evitada, em razão do efeito salino e, em algumas situações, em razão das perdas por lixiviação, principalmente em solos arenosos, com baixa capacidade de troca de cátions (BERNARDI et al., 2009).

Segundo Vieira e Texeira (2004), fertilizantes revestidos por polímeros comparados com o uso de adubos sem revestimento, não diferem quanto a época de aplicação. As diferenças ocorrem quanto a eficiência da adubação, pois fertilizantes com polímeros conferem menores perdas de nutrientes por lixiviação, volatilização e fixação, possibilitando reduzir a dose aplicada (ZAHRANI, 2000). Essa maior eficiência é proporcionada pela estrutura dos grânulos dos fertilizantes revestidos por polímeros, os quais ao absorverem água do solo, solubilizam os nutrientes no interior das cápsulas, que são gradativamente liberados por meio da estrutura porosa na zona da raiz, de acordo com a necessidade das plantas (SHAVIV, 1999; HANAFI et al., 2000; TOMASZEWSKA et al., 2002).

Os fertilizantes de liberação controlada são recobertos por substâncias orgânicas, inorgânicas ou resinas sintéticas. Tais substâncias são, em sua maioria, derivadas de uréia, como poliamidas, de enxofre elementar ou, ainda, de polímeros das mais diversas naturezas. A espessura e a natureza química da resina de recobrimento, a quantidade de microfissuras em sua superfície e o tamanho do grânulo do fertilizante determinam a taxa de liberação de nutrientes ao longo do tempo (GIRARDI; MOURÃO FILHO, 2003).

A maioria dos trabalhos com fertilizantes de liberação controlada foram desenvolvidos em outros países, sob condições diferentes das do Brasil, o que torna necessária a condução de experimentos envolvendo fertilizantes revestidos por polímeros em condições edafoclimáticas brasileiras, em especial em regiões que apresentam grande potencial à produção de grãos, a exemplo da região do cerrado. Tais trabalhos são de extrema valia, pois permitem estabelecer relações custo-benefício, bem como quantificar a eficiência agronômica da adubação, validando, dessa forma, o emprego desse tipo de fertilizante (GIRARDI; MOURÃO FILHO, 2003).

Diante do exposto, conduziu-se este trabalho, com o objetivo de comparar fontes, épocas e doses de aplicação de superfosfato triplo e cloreto de potássio revestidos ou não por polímeros no desempenho produtivo da soja em condições edafoclimáticas do cerrado.

\section{MATERIAL E MÉTODOS}

O experimento foi instalado em Latossolo Vermelho distroférrico, no município de Rio Verde, GO, com localização geográfica de $20^{\circ} 45^{\prime} 53^{\prime}$ ' de latitude sul e $51^{\circ}$ 55' 53' ' de longitude oeste e altitude de $748 \mathrm{~m}$. Os resultados da análise química de solo, na profundidade de $0-20 \mathrm{~cm}$, foi o seguinte: $\mathrm{pH}_{\text {(em água) }}=6,3 ; \mathrm{C}_{\text {org }}=30,1 \mathrm{mg} \mathrm{dm}^{-3} ; \mathrm{P}_{\text {(Mehlich I) }}=$ $8,7 \mathrm{mg} \mathrm{dm}^{-3} ; \mathrm{K}=0,99 \mathrm{cmol}_{\mathrm{c}} / \mathrm{dm}^{3} ; \mathrm{Ca}=9,40 \mathrm{cmol}_{\mathrm{c}} / \mathrm{dm}^{3} ; \mathrm{Mg}=$ $2,73 \mathrm{cmol}_{\mathrm{c}} / \mathrm{dm}^{3} ; \mathrm{Al}=0,0 \mathrm{cmol}_{\mathrm{c}} / \mathrm{dm}^{3} ; \mathrm{V}=70,5 \%$. Este apresentava textura média ( $50 \mathrm{~g} \mathrm{~kg}^{-1}$ de argila, $12 \mathrm{~g} \mathrm{~kg}^{-1} \mathrm{de}$ silte e $38 \mathrm{~g} \mathrm{~kg}^{-1} \mathrm{de}$ areia). De acordo com Empresa Brasileira de Pesquisa Agropecuária - Embrapa (2006), os níveis de $\mathrm{P}, \mathrm{K}, \mathrm{Ca}, \mathrm{Mg}$ e Al desse solo para o cultivo da cultura da soja é bom, acima do valor crítico, alto, alto e baixo respectivamente nessa ordem para cada elemento listado anteriormente. Sendo assim, a adubação de P e K utilizadas nos tratamentos foi calculada de acordo com recomendações da Embrapa (2006), onde mencionam que quando o nível de $\mathrm{P}$ no solo estiver classificado como bom e o de potássio estiver acima do valor crítico $(0,13 \mathrm{cmolc}$ $\mathrm{dm}^{-3}$ ), deve-se usar somente a adubação de manutenção, que corresponde a $20 \mathrm{~kg}$ de $\mathrm{P}_{2} \mathrm{O}_{5} \mathrm{ha}^{-1}$ e $20 \mathrm{~kg}$ de $\mathrm{K}_{2} \mathrm{O}$ ha $^{-1}$, para cada $1000 \mathrm{~kg}$ de grãos produzidos.

Os tratamentos foram estabelecidos em esquema fatorial $2 \times 2 \times 2+1$, com delineamento experimental em blocos ao acaso com quatro repetições. $\mathrm{O}$ primeiro fator foram duas fontes dos fertilizantes superfosfato triplo e 
cloreto de potássio (convencional e revestida por polímeros); o segundo, duas doses de aplicação [40 kg ha $^{-1}$ de $\mathrm{P}_{2} \mathrm{O}_{5}+40 \mathrm{~kg} \mathrm{ha}^{-1}$ de $\mathrm{K}_{2} \mathrm{O}(50 \%)$ e $80 \mathrm{~kg} \mathrm{ha}^{-1} \mathrm{de}$ $\mathrm{P}_{2} \mathrm{O}_{5}+80 \mathrm{~kg} \mathrm{ha}^{-1}$ de $\left.\mathrm{K}_{2} \mathrm{O}(100 \%)\right]$ e o terceiro, duas épocas de aplicação (na semeadura e 15 dias antes da semeadura). Adicionalmente, inclui-se um tratamento testemunha sem a aplicação de fertilizante. O revestimento dos fertilizantes foi feito 30 dias antes da aplicação com polímeros da linha Kimcoat, fornecidos pela industria química Kimberlit Ltda ${ }^{\circledR}$. Os tratamentos com adubação antecipada foram aplicados a lanço sobre a superfície do solo, enquanto que na semeadura de forma localizada. As parcelas possuíram cinco fileiras com $4 \mathrm{~m}$ de comprimento.

$\mathrm{O}$ experimento foi instalado em sucessão à cultura do milho em sistema plantio direto e dessa forma, a área foi deixada em pousio com a palhada de milho até a semeadura da cultura da soja. A área foi dessecada utilizando herbicida com glyphosate, na dose de 960 g i.a ha ${ }^{-1}$. Antes da semeadura, as sementes foram tratadas utilizando o fungicida Carbendazin e o inseticida Fipronil, ambos na dosagem de $800 \mathrm{~mL}$ para $400 \mathrm{~kg}$ de semente de soja e, posteriormente, realizou-se a inoculação da soja com Bradirizobium japonicum estirpes Semia 587 e Semia 8079. A semeadura da soja cultivar BRS-316 foi realizada em 18/ 11/2008, distribuindo-se 14 sementes por metro no sulco no espaçamento de $0,45 \mathrm{~m}$ (311.000 plantas ha $\left.\mathrm{a}^{-1}\right)$. Na ocasião, foi distribuída manualmente a adubação no sulco de semeadura de acordo com as doses de cada tratamento. As parcelas possuíam 5 fileiras de plantas de $4 \mathrm{~m}$ de comprimento.

O controle de plantas invasoras em pósemergência foi realizado utilizando-se os herbicidas com Chlorimuron-ethyl $\left(0,08 \mathrm{~L} \mathrm{ha}^{-1}\right)$ e Lactofen $\left(0,75 \mathrm{~L} \mathrm{ha}^{-1}\right)$ aos 25 dias após a emergência (DAE). A partir dos 60 DAE, procurou-se identificar focos de ferrugem asiática. Nesse período, foi aplicado o fungicida trifloxystrobin + ciproconazole $\left(300 \mathrm{~mL} \mathrm{ha}^{-1}\right)$, preventivamente, uma vez que a doença não foi encontrada. Juntamente com essa aplicação, foi realizado o controle de percevejos com uma aplicação do inseticida Permetrina $\left(65 \mathrm{~mL} \mathrm{ha}^{-1}\right)$. Doze dias após esta aplicação, foi aplicado fungicida azoxystrobin + ciproconazole $\left(300 \mathrm{~mL} \mathrm{ha}^{-1}\right)$.

Aos 60 DAE (estádio fenológico R2), foram realizadas avaliações da produção de matéria fresca e seca da parte aérea das plantas de soja, onde se procedeu o corte rente ao solo de plantas de soja contidas em área útil de $1,0 \mathrm{~m}^{2}$. As amostras foram acondicionadas em sacos de papel e sua massa fresca foi determinada por meio de balança de precisão. Posteriormente, retirou-se uma amostra da massa fresca coletada na área útil de $1,0 \mathrm{~m}^{2} \mathrm{e}$ acondicionou-a em estufa de ventilação forçada a uma temperatura de $65^{\circ} \mathrm{C}$, por 72 horas, para quantificar a produção de MS da parte aérea das plantas.

Aos 115 DAE (maturação de colheita), foi realizada a colheita manual do experimento e avaliação da massa de 1000 grãos, do número de vagens por planta e produtividade da cultura da soja. Para a avaliação do número de vagens por planta, foram separadas 10 plantas no momento da colheita e destas foram contadas a quantidade de vagens presentes em cada planta e a partir desses valores realizaram-se médias para cada tratamento. A avaliação da produtividade de soja foi realizada em uma área útil equivalente a $2 \mathrm{~m}^{2}$ no centro da parcela. Após a colheita, os grãos colhidos em cada parcela foram beneficiados, pesados e a umidade determinada e corrigida para $13 \%$. Após esta avaliação foi avaliado o peso de 1000 grãos.

Os dados foram submetidos à análise de variância, comparando-se as médias dos fatores fontes, doses e épocas de aplicação de fertilizantes pelo teste de Tukey (5\%), com o auxílio do sofware Assistat (SILVA;AZEVEDO, 2002). Para a comparação dos fatores estudados versus o tratamentos adicional (testemunha) foi utilizado o teste bilateral de Dunnet a 5\%.

\section{RESULTADOS E DISCUSSÃO}

Não houve efeito de nenhum dos fatores avaliados sobre as variáveis matéria fresca da parte aérea e massa de 1000 grãos. A média da massa de 1000 grãos avaliada do experimento foi de $149 \mathrm{~g}$, essa massa de grãos ficou acima da média das principais cultivares de soja plantada em Goiás que é de $135 \mathrm{~g}$ (EMBRAPA, 2006).

Para todas as demais variáveis, determinou-se diferença dos tratamentos com adubação relativamente à testemunha (Tabela 1).

A ausência de $\mathrm{Pe} \mathrm{K}$ (Testemunha) e, em algumas situações, aplicação de dose baixa desses nutrientes prejudica a produção de massa fresca e produtividade da cultura da soja, porém, em algumas variáveis, como a massa seca da parte aérea e o número de vagens por planta, a dose de $50 \%$ da adubação propiciou resultados similares à testemunha, demonstrando que tais adubações foram insuficientes para acarretar melhores resultados. Dessa forma, destaca-se a importância da adubação com fósforo e potássio para um bom desenvolvimento da cultura da soja, pois com um manejo eficiente da fertilidade do solo, que envolve correção da acidez e adubação recomendada para a cultura, criam-se condições ideais para a nutrição mineral da cultura da soja (TANAKA et al., 1993). 
A produção de massa seca de parte aérea foi influenciada pela interação dos fatores fonte e época de aplicação dos fertilizantes fosfatado e potássico (Tabela 2). A adubação com fertilizantes convencionais não influenciaram a produção de matéria seca das plantas de soja, independentemente da época de adubação, enquanto que a aplicação de fertilizante revestido com polímeros proporcionou maior produção de matéria seca quando aplicado antecipadamente à semeadura.

A utilização de fertilizantes revestidos por polímeros apresentou maior produção de massa seca de parte aérea do que os fertilizantes convencionais, quando estes foram aplicados a lanço, 15 dias antes da semeadura da soja. Diante de tal resultado, pode-se inferir que o maior desenvolvimento das plantas é decorrente da maior disponibilidade de $\mathrm{P}$ e $\mathrm{K}$ pelos fertilizantes revestidos por polímeros que, em condição de maior exposição do fertilizante fosfatado com o solo, possa ter reduzido a fixação do P às partículas do solo e, consequentemente, aumentou seu aproveitamento pela planta. Alguns trabalhos realizados com fertilizantes revestidos por polímeros demonstram que no geral um dos fatores que conferem melhor desempenho das plantas a aplicação destes fertilizantes é o fornecimento regular e contínuo de nutrientes às plantas, redução de perdas de potássio por lixiviação, e fósforo por adsorção (SHAVIV, 2001; MENDONÇA et al., 2004). Por outro lado, a aplicação de fertilizante convencional a lanço antecipado faz com que o fertilizante entre em contato direto com os colóides do solo, possibilitando adsorção e fixação de $\mathrm{P}$, reduzindo o aproveitamento imediato desse nutriente pela planta (GOMES et al., 2005).

Também a produtividade de grãos não sofreu efeito entre os fatores fonte e dose de fertilizantes. Porém, essa variável e o número de vagens por planta foram influenciados pela interação entre a época de aplicação e as fontes de nutrientes (Tabela 3 ).

Tabela 1 - Produção de massa fresca (MF), massa seca (MS), número de vagens por planta (NVP) e produtividade (PROD) da cultura da soja em função da aplicação dos tratamentos.

\begin{tabular}{lcccc}
\hline \multicolumn{1}{c}{ Tratamento } & MF $\left(\mathrm{Mg} \mathrm{ha}^{-1}\right)$ & MS $\left(\mathrm{Mg} \mathrm{ha}^{-1}\right)$ & NVP & PROD $\left(\mathrm{Mg} \mathrm{ha}^{-1}\right)$ \\
\hline FC - 100\% - na semeadura & $15,12 \mathrm{a}^{*}$ & $5,29 \mathrm{a}$ & $95,25 \mathrm{a}$ & $3,16 \mathrm{a}$ \\
FC - 100\% - 15 DAS & $15,39 \mathrm{a}$ & $4,41 \mathrm{a}$ & $92,50 \mathrm{a}$ & $3,11 \mathrm{a}$ \\
FC - 50\% - na semeadura & $12,46 \mathrm{a}$ & $3,57 \mathrm{~b}$ & $77,25 \mathrm{a}$ & $3,06 \mathrm{a}$ \\
FC - 50\% - 15 DAS & $12,69 \mathrm{a}$ & $4,99 \mathrm{a}$ & $64,75 \mathrm{~b}$ & $2,89 \mathrm{a}$ \\
FRP - 100\% - na semeadura & $15,37 \mathrm{a}$ & $4,65 \mathrm{a}$ & $119,50 \mathrm{a}$ & $3,22 \mathrm{a}$ \\
FRP - 100\% - 15 DAS & $15,18 \mathrm{a}$ & $5,88 \mathrm{a}$ & $118,75 \mathrm{a}$ & $3,25 \mathrm{a}$ \\
FRP - 50\% - na semeadura & $14,53 \mathrm{a}$ & $3,58 \mathrm{~b}$ & $95,25 \mathrm{a}$ & $3,10 \mathrm{a}$ \\
FRP - 50\% - 15 DAS & $12,22 \mathrm{a}$ & $4,46 \mathrm{a}$ & $91,50 \mathrm{a}$ & $3,18 \mathrm{a}$ \\
Testemunha & $9,68 \mathrm{~b}$ & $2,83 \mathrm{~b}$ & $62,75 \mathrm{~b}$ & $2,50 \mathrm{~b}$ \\
\hline
\end{tabular}

* Médias seguidas de mesma letra, nas colunas, não diferem estatisticamente entre si pelo teste de Dunnet $(\mathrm{p}<0,05)$.

Tabela 2 - Produção de matéria seca de parte aérea das plantas de soja $\left(\mathrm{Mg} \mathrm{ha}^{-1}\right)$ em sistema plantio direto, determinadas aos 60 DAE, em função da época de aplicação e da fonte de fósforo e potássio.

\begin{tabular}{ccc}
\hline \multirow{2}{*}{ Fonte de P e K } & \multicolumn{2}{c}{ Épocas de aplicação $^{1}$} \\
\cline { 2 - 3 } & Antecipada & Semeadura \\
\hline Convencional & $4,70 \mathrm{bA}^{*}$ & $4,44 \mathrm{aA}$ \\
Revestida com polímeros & $5,17 \mathrm{aA}$ & $4,12 \mathrm{aB}$ \\
\hline
\end{tabular}

C.V $(\%)=9,54$

\footnotetext{
${ }^{1}$ Antecipada: aplicação a lanço 15 dias antes da semeadura; semeadura: aplicação localizada no sulco de plantio, por ocasião da semeadura. *Médias seguidas pela mesma letra, minúscula na coluna e maiúscula na linha, não diferem estatisticamente entre si pelo teste de Tukey $(\mathrm{p}<0,05)$.
} 
Tabela 3 - Número de vagens por planta (NVP) e produtividade de grãos de soja em sistema plantio direto, decorrente da aplicação de fertilizantes com e sem revestimento por polímeros, aplicados a lanço antecipado (15 dias antes da semeadura) ou em semeadura.

\begin{tabular}{ccccc}
\hline \multirow{2}{*}{ Fonte de P e K } & \multicolumn{2}{c}{ Número de Vagens } & \multicolumn{2}{c}{ Produtividade de grãos $\left(\mathrm{kg} \mathrm{ha}^{-1}\right)$} \\
\cline { 2 - 5 } & Antecipada & Semeadura & Antecipada & Semeadura \\
\hline Convencional & $78,62 \mathrm{bB}$ & $86,25 \mathrm{bA}$ & $3002,3 \mathrm{bB}$ & $3106,5 \mathrm{aA}$ \\
Revestida com polímeros & $105,12 \mathrm{aA}^{*}$ & $107,37 \mathrm{aA}$ & $3217,6 \mathrm{aA}$ & $3161,3 \mathrm{aA}$ \\
\hline C.V $(\%)$ & \multicolumn{3}{c}{2,82} & 1,91 \\
\hline
\end{tabular}

* Médias seguidas pela mesma letra, minúscula na coluna e maiúscula na linha, não diferem estatisticamente entre si pelo teste de Tukey $(<0,05)$.

Ao utilizar fertilizante convencional, nota-se que os maiores valores de número de vagens por planta e produtividade foram obtidos quando esses fertilizantes foram aplicados na semeadura, enquanto que, com o emprego de fertilizante revestido por polímero, o número de vagens por planta e a produtividade foram estatisticamente iguais entre as épocas de aplicação. Diante disso, é possível verificar que os fertilizantes revestidos por polímeros viabilizaram a aplicação a lanço, 15 dias antes da semeadura da soja em relação à aplicação localizada no sulco de plantio na semeadura, trazendo o benefício de agilizar a operação de implantação da cultura da soja. Tais resultados estão de acordo com Vieira e Texeira (2004), ao mencionarem que os fertilizantes revestidos por polímeros comparados com fertilizante convencional, diferem quanto a sua eficiência, pois reduzem as perdas por lixiviação, volatilização e fixação.

Os fertilizantes revestidos por polímeros, independente da época de sua aplicação, produziram maior número de vagem por planta que os fertilizantes convencionais, porém em relação a produtividade de grãos, nota-se que os fertilizantes revestidos por polímeros só geraram maior produtividade que os fertilizantes convencionais quando esses fertilizantes foram aplicados a lanço antecipado, enquanto que a aplicação junto a semeadura proporcionou produtividades equivalentes entre as duas fontes de fertilizantes. Esses resultados nos mostram que os fertilizantes revestidos por polímeros, por terem menores perdas por adsorção de $\mathrm{P}$ e lixiviação de $\mathrm{K}$, proporcionam uma melhor nutrição da planta quando os fertilizantes foram aplicados antecipadamente.

Não foi constatada nenhuma interação entre as fontes e doses de fósforo e potássio aplicados nesse experimento, sendo assim, acredita-se que o bom estado de fertilidade do solo possa ter encoberto o efeito e a diferença das doses analisadas.

\section{CONCLUSÕES}

Houve resposta à aplicação da adubação com P e $\mathrm{K}$ na produção de massa fresca e produtividade, sendo a ausência de adubação prejudicial ao desenvolvimento da cultura da soja.

Nas condições deste trabalho, a aplicação a lanço 15 dias antecipados à semeadura por meio de fertilizantes revestidos por polímeros, conferiu maior produção de massa seca, número de vagens por planta e produtividade de grãos de soja em relação aos fertilizantes convencionais, sendo assim, percebe-se que os fertilizantes revestidos por polímeros são mais eficientes para garantir a nutrição mineral das plantas quando se visa a uma aplicação antecipada à semeadura.

Quando aplicados por ocasião da semeadura, os fertilizantes convencionais e os revestidos por polímeros proporcionam mesma produção de massa seca e produtividade de grãos de soja.

\section{REFERÊNCIAS BIBLIOGRÁFICAS}

AMOACY, F.C. Adubação na superfície ou incorporada? Piracicaba, Plantio Direto, v. 01, n.73, p.35, 2006.

BERNARDI, A.C.C. de et al. Doses e formas de aplicação da adubação potássica na rotação soja, milheto e algodão em sistema plantio direto. Pesquisa

Agropecuária Tropical, Brasília, v.39, n.2, p.158-167, 2009.

COMPANHIA NACIONAL DEABASTECIMENTO.

Custos de produção das culturas de verão da safra 2010/11. Disponível em: $\langle\bar{h} \overline{t t p}: / / \mathrm{WWw}$.conab.gov.bri 'conteudos.php? Acesso em: 23 out. 2010. 
EMPRESA BRASILEIRA DE PESQUISA AGROPECUÁRIA. Tecnologias de produção de soja: região central do Brasil, 2007. Londrina: Embrapa, 2006. 225 p.

GIRARDI, E.A.; MOURÃO FILHO, F.A.A. Emprego de fertilizantes de liberação lenta na formação de pomares de citros. Revista Laranja, Cordeirópolis, v.24, n.2, p.507-518, 2003.

GOMES, J.A.et al. Adubações orgânica e mineral, produtividade do milho e características físicas e químicas de um Argissolo Vermelho-Amarelo. Acta Scientiarum Agronomy, Maringá, v.27, n.3, p.521-529, 2005.

GUARESCHI, R.F.et al. Adubação fosfatada e potássica na semeadura e a lanço antecipada na cultura da soja cultivada em solo de Cerrado. Semina: Ciências Agrárias, Londrina, v.29, n.4, p.93-98, 2008.

HANAFI, M.M.; ELTAIB, S.M.; AHMAD, M.B. Physical and chemical characteristics of controlled release compound fertilizer. European Polymer Journal, Oxford, v.36, p.2081-2088, 2000.

LANA, R.M.Q.; VILELA FILHO, C.E.; ZANÃO JÚNIOR, L.A. Adubação superficial com fósforo e potássio para a soja em diferentes épocas em pré-semeadura na instalação do plantio direto. Scientia Agricola, Curitiba, v.4, n.1/2, p.53-60, 2003.

MATOS, M.A.; SALVI, J.V.; MILAN, M. Pontualidade na operação de semeadura e a antecipação da adubação e suas influências na receita líquida da cultura da soja. Engenharia Agrícola, Jaboticabal, v.26, n.2, p.493-501, 2006.

MENDONÇA, V. et al. Osmocote ${ }^{\circledR}$ e substratos alternativos na produção de mudas de maracujazeiroamarelo. Ciência e Agrotecnologia, Lavras, v.28, n.4, p.799-806, jul./ago. 2004.

MENDONÇA, V. et al. Fertilizante de liberação lenta na formação de mudas de maracujazeiro 'amarelo'. Ciência e Agrotecnologia, Lavras, v.31, n.2, p.344-348, mar./abr. 2007.
PAVINATO, P.S.; CERETTA, C.A. Fósforo e potássio na sucessão trigo/milho: épocas e formas de aplicação.

Ciência Rural, Santa Maria, v.34, n.6, p.1779-1784, 2004.

PÖTTKER, D. Modos de aplicação de fósforo para uma sequência de culturas em plantio direto. Revista Plantio Direto, Passo Fundo, v.53, n.5, p.15, out. 1999.

SHAVIV, A. Advances in controlled-release fertilizers. Advances in Agronomy, Newark, v.71, n.5, p.1-49, 2001.

SHAVIV, A. Preparation methods and release mechanisms of controlled release fertilizers: agronomic efficiency and environmental significancy. Proceedings of the Fertiliser Society, York, v.41, n.3, p.1-35, 1999.

SILVA, F.A.S. de; AZEVEDO, C.A.V. de. Versão do programa computacional Assistat para o sistema operacional Windows. Revista Brasileira de Produtos Agroindustriais, Campina Grande, v.4, n.1, p.71-78, 2002.

SILVA, R.H.; ROSOLEM, C.A. Influência da cultura anterior e da compactação do solo na absorção de macronutrientes em soja. Pesquisa Agropecuária Brasileira, Brasília, v.36, n.10, p.1269-1275, out. 2001.

TANAKA, R.T.; MASCARENHAS, H.A.A.; BORKERT, C.M. Nutrição mineral da soja. In: Cultura da soja nos cerrados. Piracicaba: Potafos, 1993. p.105-135.

TOMASZEWSKA, M.; JARPSOEWICZ, A.; KARAKKULSKI, K. Physical and chemical characteristics of polymer coatings in CRF formulation. Deslination, Nottingham, v.146, n.3, p.319-323, 2002.

VIEIRA, B.A.R.M. de; TEIXEIRA, M.M. Adubação de liberação controlada chega como solução. Revista Campo \& Negócios, Uberlândia, v.41, n.3, p.4-8, 2004.

ZAHRANI, S. Utilization of polyethylene and paraffin waxes as controlled delivery systems for different fertilizers. Industrial \& Engineering Chemistry Research, Washington, v.39, n.3, p.367-371, 2000. 